\title{
Situação vacinal de crianças assistidas na rede de atenção básica de São Luís: período de agosto de 2013 a julho de 2014
}

\author{
Assisted children's vaccine situation in primary care network of São Luis: in august \\ 2013 to july 2014
}

\author{
Paulo Roberto da Silva Marques ${ }^{1}$, Ilis Maria Lucas Xavier ${ }^{2}$
}

\begin{abstract}
Resumo: Introdução: Vacinação é o conjunto de mecanismos através dos quais o organismo humano reconhece uma substância como estranha para, em seguida, metabolizá-la e produzir resposta imune. Vacinar é sinônimo de prevenção, sendo assim, imprescindível saber a situação vacinal de um local, para se tomar as medidas adequadas para melhorias na cobertura vacinal. Objetivo: Avaliar a situação vacinal infantil na rede de Atenção Básica em São Luís- Maranhão. Materiais e Métodos: Este trabalho trata-se de um estudo quantitativo, descritivo, transversal do Programa de Educação pelo Trabalho da Universidade Ceuma. As variáveis descritivas foram avaliadas através de gráficos, percentuais e tabelas de frequências. As variáveis em estudo foram avaliadas pelo teste do Qui-quadrado, sendo a escolaridade avaliada pelo Teste Exato de Fisher, e o resultado final pelo teste do t Student. Resultados: Foram avaliadas 126 Cadernetas de Vacinação, dos quais $65,87 \%$ (83) crianças estavam em atraso, enquanto apenas 34,12\% (43) encontrava-se em dia $(p=0,040)$. Conclusão: A cobertura vacinal ainda não é efetiva em São Luís-Maranhão. Seja por dificuldade do sequenciamento de vacinas, seja por uma situação familiar conturbada, e vários outros motivos, mas o certo é que há uma necessidade imediata de se melhorar a cobertura vacinal dessas crianças.
\end{abstract}

Palavras-chave:Crianças. Vacinação. Prevenção.

\begin{abstract}
Introduction: Vaccination is the set of mechanisms by which the human body recognizes as foreign substance to then metabolize it, and producing immune response. Vaccinating is synonymous with prevention, therefore, essential to know the vaccination status of a site, to take appropriate measures to improvements in immunization coverage. Objective: To assess the children's immunization status on the network of Primary Care in São Luís Maranhão. Materials and Methods: This work it is a quantitative, descriptive, cross-sectional, the Program of Education for Work at the University Ceuma. Descriptive variables were evaluated through graphs, percentages and frequency tables. The variables were evaluated by chi-square test, the education evaluated by Fisher's exact test, and the final result by the Student $t$ test. Results: A total of 126 vaccination certificates, of which $65.87 \%$ (83) children were in arrears, while only $34.12 \%(43)$ was in days $(p=$ 0.040). Conclusion: Vaccination coverage is not effective in São Luís, Maranhão. Or by difficulty sequencing of vaccines, either by a troubled family situation, and various other reasons, but the fact is that there is an immediate need to improve vaccination coverage of these children.
\end{abstract}

Keywords: Children. Vaccination. Prevention.

1 - Graduado do Curso de Medicina - UNICEUMA

2- Docente - UNICEUMA

Rev. Investig. Bioméd. São Luís 8:6-20. 2016 
Introdução

Compreende-se por vacinação um conjunto de mecanismos através dos quais o organismo humano reconhece uma substância como estranha para, em seguida, metabolizá-la e produzir resposta imune. ${ }^{1}$

O termo imunidade é proveniente da palavra immunitas, que significa isenção de cargos ou processos legais. Significa proteção contra agentes infecciosos. Ela é dividida em Imunidade Natural e Específica. $\mathrm{Na}$ primeira, destacam-se barreiras mecânicas, secreção cutânea, secreção mucosa, fatores séricos e teciduais. Já a segunda é responsável por produzir resposta imunológica natural ou estimulada contra determinado antígeno. Para as crianças, em especial, esse conceito se torna mais importante, já que o sistema imunológico dos pequenos ainda não reconhece os agentes causadores de doenças o que as torna mais suscetíveis aos agravos. ${ }^{2}$

As vacinas são geralmente produzidas a partir de agentes patogênicos (vírus ou bactérias), ou ainda de toxinas, previamente enfraquecidos. Ao inserir no organismo esse tipo de substâncias, fazemos com que o corpo combata o agente estimulando a síntese de anticorpos, que protegem o nosso organismo, além de desenvolver a chamada memória imunológica, tornando mais fácil o reconhecimento do agente patogênico em futuras infecções e aumentando a eficiência do sistema imune em combatê-lo. Quando o corpo é atacado por algum agente patogênico não chega a desenvolver a doença porque o organismo encontrase protegido. ${ }^{3}$

As vacinas são classificadas em vivo-atenuadas, quando a virulência (patogenicidade) do agente infeccioso é reduzida de forma segura, para não causar a doença. Exemplos de vacinais virais: febre amarela, sarampo, caxumba, pólio (Sabin), rubéola e varicela zoster (catapora). Vacina bacteriana: Bacillus CalmetteGuérin (BCG) - tuberculose. ${ }^{4}$ Elas também são classificadas em inativadas ou inertes, quando o agente infeccioso é inativado, e torna-se incapaz de se multiplicar, mas apresenta sua estrutura e seus componentes, preservando a capacidade de estimular o sistema imunológico. São exemplos dessas vacinas: Hepatite B e A, Pentavalente $(\mathrm{DTP}+\mathrm{Hib}+$ Hepatite B), Pneumocócica e Meningocócica. ${ }^{5}$

Historicamente, o Programa Nacional de Imunização (PNI) já logrou alguns êxitos, muito em parte, por sua maneira articulada de funcionamento, com campanhas de vacinação e conscientização populacional, a exemplos disso, cita-se a erradicação da varíola em 1973 e da poliomielite em 1989. E o controle de outras doenças, como o sarampo, o tétano neonatal, formas graves da tuberculose, a difteria, o tétano acidental e a coqueluche. ${ }^{6}$

Embora exista todo esse esforço governamental para atualização da situação vacinal, por vezes ainda encontram-se calendários vacinais desatualizados, o que coloca a população, em especial 0 público infantil, em risco de saúde, de forma que tem chamado atenção do governo e dos agentes promotores de saúde para os reais motivos que levam os familiares e os pais a não darem continuidade a todo o processo de vacinação. $^{7}$

Nesse contexto, o PNI expande campanhas de vacinação e sua meta de imunização para a população em geral, priorizando, em especial, as crianças. Estas, por não possuírem um sistema imune já formado, se tornam 
suscetíveis a vários agravos. Tendo isso em vista, o Ministério da Saúde criou um esquema que pudesse desenvolver a resposta imunológica desses pequenos, é 0 que conhecemos como calendário vacinal infantil, ele é constituído pelas seguintes Vacinas, segundo a Base de Dados do Sistema Único de Saúde (DATA-SUS)- PNI: BCG, Hepatite B, Vacina Inativada Poliomielite (VIP) e Vacina oral poliomielite (VOP), Rotavírus, Febre Amarela, Tríplice Bacteriana, Pneumocócica, Meningocócica. ${ }^{8}$

De maneira que o objetivo geral foi avaliar a situação vacinal das crianças assistidas na rede de Atenção Básica em São Luís - Maranhão. Sendo norteado pelos seguintes objetivos específicos: Verificar a relação entre condição socioeconômica das famílias com a situação do calendário vacinal; Relatar as vacinas mais desatualizadas; Comparar a situação vacinal por faixa etária.

A resposta orgânica às vacinas depende de dois fatores: os inerentes às vacinas e os relacionados com 0 próprio organismo. As vacinas estimulam a produção de anticorpos, especificamente contra 0 agente infeccioso e seus produtos tóxicos; desencadeando uma resposta imune própria, com o objetivo de formar células de memória, para proteção contra um futuro contágio; sendo que a pessoa vacinada previne a doença, sem os riscos da própria infecção. ${ }^{9}$

O calendário vacinal infantil atualmente é constituído pela BCG, Hepatite B, Tríplice Bacteriana, Pentavalente, VIP/VOP, Pneumocócica Conjugada, Meningocócica, Rotavírus, Influenza, Tríplice Viral, Hepatite A, Febre Amarela e o Human Papiloma Virus (HPV). Das quais, Hepatite A,
Influenza e HPV não foram incluídas neste estudo.

A BCG, Bacilo de Calmette e Guérin, é uma vacina atenuada da cepa de Mycobacterium bovis. Em nosso país, a estirpe da bactéria utilizada é altamente imunogênica. Ela é capaz de estimular tanto a resposta humoral quanto a celular, e promover imunidade contra a Tuberculose. Está indicada em países com alta prevalência da doença. Via de administração intradérmica no deltóide direito, aplicar ao nascimento no volume de $0,1 \mathrm{~mL}$. A aplicação precoce do BCG visa reduzir a incidência das formas graves da doença, tais como a tuberculose meníngea e a tuberculose miliar. ${ }^{10}$

A Hepatite $B$ é derivada do vírus de ácido desoxirribonucléico (DNA), membro da família Hepadnaviridae. A vacina contra hepatite $B$ tem se mostrado capaz de reduzir o estado de portador crônico, além de evitar a cirrose, bem como o hepatocarcinoma, uma vez que crianças infectadas pelo vírus $B$ evoluem mais frequentemente para manifestações crônicas do vírus. A idade de aplicação da primeira dose é ao nascimento (preferencialmente nas primeiras 12 horas devida), a segunda, um mês após a primeira, e a terceira, 6 meses após a primeira. Podendo começar em qualquer idade. $^{10}$

A tríplice bacteriana é composta por Difteria, Tétano e Coqueluche, devem ser administradas na aplicação de três doses, com intervalo de 60 dias(mínimo de 30 dias), a partir de dois meses de idade. ${ }^{10}$

Os dois reforços necessários serão realizados com a vacina difteria, tétano e pertussis (DTP). O primeiro reforço é aos 15 meses e o segundo aos 4 anos. A difteria, doença causada pelo bacilo Coryne bacterium diphtheriae, frequentemente se aloja nas amígdalas, faringe, laringe, nariz. 
A transmissão se dá pelo contato direto de pessoa doente ou portadores com pessoa suscetível, através de gotículas de secreção respiratória, eliminadas por tosse, espirro ou ao falar. Em casos raros, pode ocorrer a contaminação por objetos compartilhados. ${ }^{10}$

Já o tétano é uma doença transmissível, não contagiosa. Ela possui duas formas de contaminação: a acidental e a neonatal. A primeira geralmente acomete pessoas que entram em contato com 0 bacilo tetânico (Clostridium tetani) ao manusearem o solo ou através de ferimentos ou lesões ocorridas por materiais contaminados. $O$ tétano neonatal é causado pela contaminação durante a secção do cordão umbilical. $^{10}$

A coqueluche é uma doença infecciosa aguda, de transmissão respiratória. Compromete especificamente 0 aparelho respiratório (traquéia e brônquios), e se caracteriza por forte tosse seca. A transmissão ocorre, principalmente, pelo contato direto de pessoa doente com pessoa suscetível, por meio de eliminação de gotículas de secreção de orofaringe eliminadas ao tossir, falar ou espirrar. $O$ agente etiológico da coqueluche é a bactéria Bordetella pertussis. $^{10}$

Outra vacina importante é a Febre Amarela. A vacina é constituída de vírus vivos atenuados, ela é aplicada a partir de nove meses em dose única por via subcutânea e repetida com 4 anos. Em caso de vacinação aos 4 anos não efetivada, deve ser feita uma nova dose. Crianças de 5 anos, nunca vacinadas, devem fazer uma dose e outra 10 anos depois. Vacinas de vírus vivos atenuados podem ser aplicadas simultaneamente. Caso estas não sejam feitas no mesmo dia da vacina contra febre amarela, deve-se esperar um intervalo mínimo de duas semanas para aplicação. ${ }^{11}$

O Rotavírus é uma vacina contra o vírus Reoviridae, que causa diarreia grave, frequentemente acompanhada de febre e vômitos. É hoje considerado um dos mais importantes agentes causadores de gastroenterites e óbitos em crianças menores de 5 anos. Ela deve ser Administrada em duas doses, seguindo rigorosamente os limites de faixa etária: primeira dose: 1 mês e 15 dias a 3 meses e 7 dias; segunda dose: 3 meses e 7 dias a 5 meses e 15 dias. ${ }^{10}$

O intervalo mínimo preconizado entre a primeira e a segunda dose é de 30 dias. Nenhuma criança poderá receber a segunda dose sem ter recebido a primeira. Se a criança regurgitar, cuspir ou vomitar após a vacinação, não se deve repetir a dose. ${ }^{10}$

Em 2010 a vacina Pneumocócica foi incluída no Calendário Básico de Vacinação da Criança, para a prevenção de meningite, pneumonia, otite média aguda, sinusite e bacteremia, que são doenças causadas pela bactéria Streptococcus pneumoniae. Ela deve ser administrada em 3 (três) doses, aos 2, 4 e 6 meses de idade. $O$ intervalo ideal entre as doses é de 60 dias e o mínimo é de 30 dias. O reforço deve ser feito entre 12 e 15 meses de idade, com intervalo mínimo de 6 meses após a $3^{\text {a }}$ dose. ${ }^{10}$

A Meningocócica previne as doenças provocadas pela bactéria Neisseria meningitidis do sorogrupo C, como a meningite. A vacinação é considerada a forma mais eficaz na prevenção desse problema. A vacina deve ser administrada em duas doses, aos 3 e 5 meses de idade, com intervalo mínimo de 30 dias e máximo de 60 dias entre as doses. O reforço é recomendado entre 12 e 15 meses de idade. $^{10}$ 
Para a Poliomielite existem dois tipos diferentes da vacina, a VIP e a VOP. A VIP - Vacina Inativada Poliomielite, é injetável, logo, mais segura, pois evita que a criança desenvolva a paralisia associada à vacina. Desde 2012 o Ministério da Saúde determinou que todas as crianças que ainda não foram imunizadas contra a Paralisia Infantil receba a vacina VIP em duas doses. As outras doses podem ser VOP, ou de acordo com a orientação do pediatra. Essa vacina é constituída por cepas inativadas (mortas) dos três tipos (1, 2 e 3 ) de poliovírus e produz anticorpos contra todos eles. ${ }^{10}$

Já a VOP Sabin, vacina pólio oral, utiliza o vírus em estado atenuado. É recomendado que todas as crianças com menos de 5 anos recebam a dose oral durante a campanha do Ministério da Saúde, desde que já tenham recebido as 2 doses da VIP. Ainda é aceitável que se faça o sequenciamento dessa vacina com 3 doses de VOP na sequência, pois esse esquema é feito em $2 ; 4 ; 6$; 15-18 meses; $4-5$ anos, com intervalo mínimo 60 dias. $^{10}$

A vacina tríplice viral é uma combinação de vírus vivos atenuados contra o sarampo, a caxumba e a rubéola. Todos os três componentes desta vacina obrigatória são altamente imunogênicos e eficazes, dando imunidade duradoura por praticamente toda a vida. A proteção inicia-se cerca de duas semanas após a vacinação, 0 sarampo é uma doença infectocontagiosa pelo vírus chamado Morbillivirus. A enfermidade causa grande mortalidade infantil em países do terceiro mundo. No Brasil, a mortalidade é baixa, principalmente pelas sucessivas campanhas de vacinação e programas de vigilância epidemiológica. A transmissão é diretamente de pessoa a pessoa, por meio das secreções do nariz e da boca expelidas pelo doente ao tossir, respirar ou falar. ${ }^{10}$

A caxumba é uma doença contagiosa que provoca o inchaço doloroso das glândulas salivares. A caxumba é causada pelo vírus Paramyxovirus, que se dissemina de uma pessoa para outra através de gotículas respiratórias ou por contato direto com itens que foram contaminados pela saliva infectada. ${ }^{10}$

A rubéola é uma exantemática, que causa grande preocupação em gestantes pelo risco de rubéola congênita, que pode deixar sequelas graves. A doença é causada por um vírus disseminado pelo ar ou por contato próximo. Uma pessoa com rubéola pode transmitir a doença a outras pessoas desde uma semana antes do início da erupção até uma a duas semanas depois do seu desaparecimento. $^{10}$

Como a vacina tríplice viral (sarampo, rubéola e caxumba) é aplicada para a maioria das crianças, a rubéola é muito menos comum atualmente. Praticamente todos os que recebem a vacina são imunes à rubéola. Em alguns adultos, a vacina pode perder a eficácia e não protegêlos completamente. Por isso, as mulheres grávidas são orientadas a se vacinar, e demais adultos a receberem um reforço ${ }^{10}$.

Um calendário básico de vacinação desatualizado pode causar diversos agravos, que podem se reverter em graves problemas de saúde pública, pois aumenta o risco de adquirir doenças imunopreveníveis, aumentando 0 risco de surgirem epidemias na comunidade. ${ }^{12}$ Sabendo disso, o governo federal vem incentivando as Estratégias de Saúde da Família (ESF), para atuar mais fortemente no que se refere à atenção primária à saúde, buscando cada dia mais o controle, prevenção ou 
erradicação

imunopreveníveis. ${ }^{13}$

doenças

Nesse sentido, apesar das dificuldades na precoce reforma sanitária brasileira, as causas que motivam 0 não sequenciamento vacinal têm sido ignoradas nos programas de vacinação em diversos países. No Brasil, apesar das campanhas, ainda existe um desinteresse populacional pela vacinação, fazendo com que esse estudo seja permanentemente discutido, com o intuito de melhorar e aumentar o acesso ao Programa de Imunização do Governo Federal. ${ }^{14}$

\section{Materiais e Métodos}

Trata-se de um estudo quantitativo, descritivo, transversal, secundário ao banco de dados do Programa de Educação pelo Trabalho da Universidade Ceuma (PET-SAÚDECEUMA), para tentar identificar a realidade da cobertura vacinal infantil na cidade de São Luís - Maranhão.

As informações foram coletadas em quatro unidades básicas de saúde (Unidade de Saúde do Pirapora - Anil, Centro de Saúde Djalma Marques Turu, Centro de Saúde Nazaré Neiva de Santana - São Raimundo, Centro de Saúde AMAR - Vicente Fialho) da Rede de Atenção Primária de São Luís Maranhão.

O público alvo foram Crianças de ambos os sexos, entre 0 e 5 anos de idade, assistidas nas Unidades Básicas de Saúde entre Agosto de 2013 a Julho de 2014. O total de participantes foram 126 crianças, que foram incluídas desde que fossem ludovicenses, com idade de 0 a 5 anos, e atendida em livre demanda nas unidades em estudo.

No contexto de desenvolvimento desta pesquisa, os riscos podem ser considerados mínimos desprezíveis. Trazendo benefícios diretos à população, mediante a identificação do quadro situacional da vacinação infantil na rede de Atenção Básica em São Luís- MA, que poderá auxiliar na formulação de medidas que aperfeiçoem este setor da atenção primária, tendo em vista que a imunização é sinônimo de qualidade de vida.

As informações coletadas foram avaliadas de acordo com os seguintes critérios: as condições sóciodemográficas, faixa etária, estado civil, auxílio governamental, escolaridade e número de filhos, e a relação com a situação vacinal, observando-se sempre quais os fatores estavam influenciando de maneira direta ou indireta no sequenciamento da imunização infantil.

Para avaliação do calendário vacinal, foi tomado como base o calendário do ano de 2013. Considerou-se em atraso as crianças que estavam com desatualização em mais de uma dose de uma vacina. A vacina foi considerada atualizada quando o cartão estava confirmado com o carimbo do posto, e preenchido adequadamente com a data e a assinatura do funcionário responsável.

Todos os dados foram analisados estatisticamente pelo programa Microsoft Excel. As variáveis descritivas foram avaliadas através de gráficos, percentuais e tabelas de frequência. As variáveis Estado Civil, Número de Filhos, Idade, Auxílio Governamental foram avaliadas pelo teste do Qui-quadrado $\left(\chi^{2}\right)$. A Escolaridade foi avaliada pelo Teste Exato de Fisher, e o resultado final teve seu erro calculado pelo teste do $t$ student. Para descrição quantitativa do trabalho, será considerada a atualização do calendário de vacinação do ano de 2013.

$$
\text { Este estudo garantiu a }
$$
confidencialidade das fontes de 
informação, sem identificação de qualquer sujeito participante no estudo. O conteúdo deste trabalho foi aprovado pelo Comitê de Ética em Pesquisa da Universidade Ceuma (parecer no 743094/12).

\section{Resultados}

Foram avaliadas 126 Cadernetas de Vacinação na Rede de Atenção Básica em São Luís. Deste total, 83 crianças estavam em atraso, configurando $66 \%$, enquanto 43 encontravam-se em dia, representando $34 \% \quad(p=0,040)$ (Gráfico 1).

Analisando-se os Cartões de Vacinação, verificou-se que a Pentavalente, a VIP/VOP e a Pneumocócica eram as vacinas que apresentaram 0 maior número de situações de desatualização, enquanto a BCG, a Hepatite B, primeira dose, e a Febre Amarela estavam todas atualizadas (tabela 1).

As dosagens em atraso de cada vacinal também foram evidenciadas de acordo com a tabela 2.

Gráfico 1 - Situação vacinal

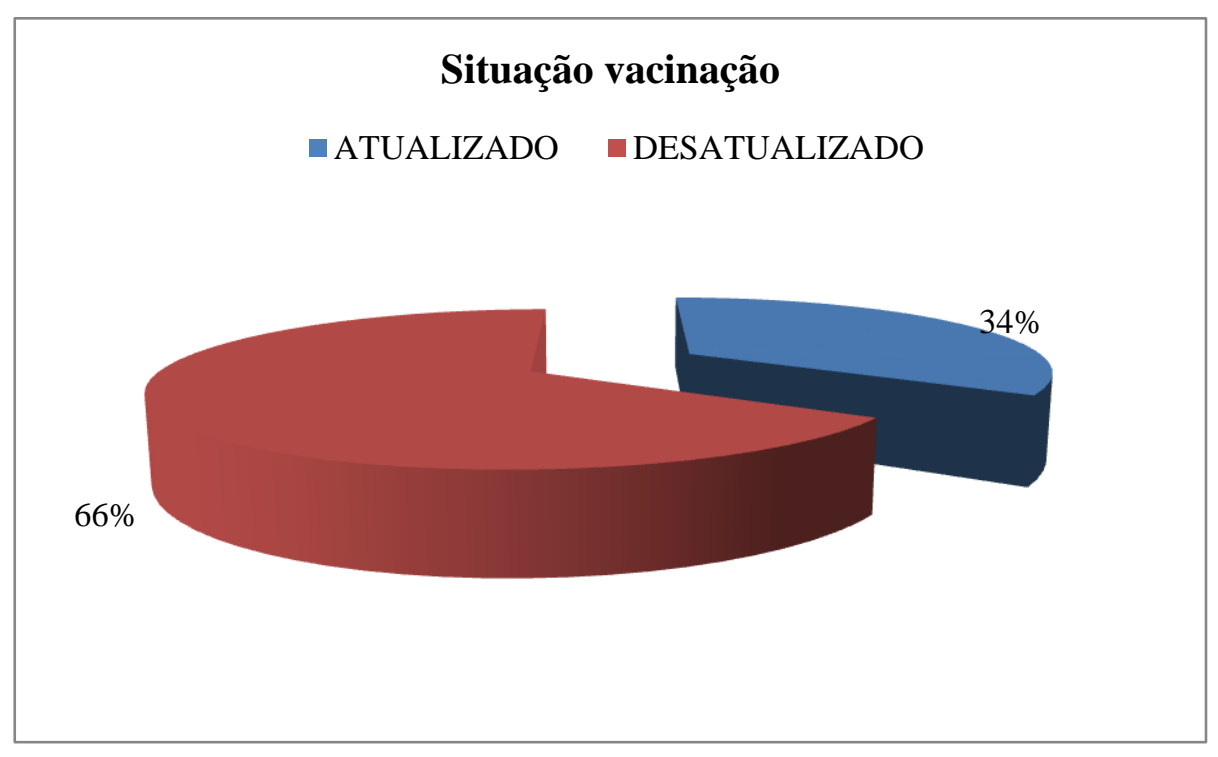

Tabela 1 - Vacinas desatualizadas

\begin{tabular}{lcc}
\hline \multicolumn{1}{c}{ Vacinas desatualizadas } & $\mathbf{n}$ & $\%$ \\
\hline BCG & 0 & 0 \\
Hepatite B & 0 & 0 \\
Pentavalente & 46 & 22,4 \\
VIP/NOP & 41 & 20,0 \\
Rotavírus & 13 & 6,3 \\
Pneumocócica & 54 & 26,3 \\
Meningocócica & 34 & 16,6 \\
Tríplice Viral & 17 & 8,3 \\
Febre Amarela & 0 & 0 \\
\hline Total & 205 & 100,0 \\
\hline
\end{tabular}


Tabela 2 - Vacinas e dosagens em atraso

\begin{tabular}{|c|c|c|c|c|c|c|c|}
\hline $\begin{array}{l}\text { Vacinas e } \\
\text { Atraso }\end{array}$ & Dosagem & $\begin{array}{l}0 \\
\& \\
0 \\
0 \\
\text { ॠ1 }\end{array}$ & 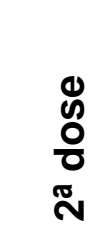 & 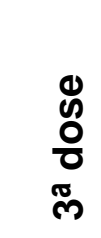 & 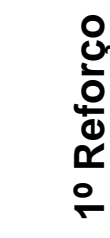 & 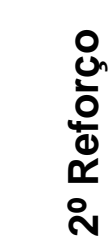 & \\
\hline$B C G$ & & 0 & - & - & - & - & 0 \\
\hline Hepatite B & & 0 & - & - & - & - & 0 \\
\hline Pentavalente & & 0 & 14 & 5 & 20 & 7 & 46 \\
\hline VIP/VOP & & 0 & 13 & - & - & - & 13 \\
\hline Rotavírus & & 0 & 20 & 7 & 11 & 3 & 41 \\
\hline Pneumocócica & & 0 & 13 & 21 & 20 & - & 54 \\
\hline Meningocócica & & 0 & 22 & 12 & - & - & 34 \\
\hline Tríplice Viral & & 0 & 17 & - & - & - & 17 \\
\hline FebreAmarela & & 0 & - & - & - & - & 0 \\
\hline TOTAL & & 0 & 99 & 45 & 51 & 10 & 100,0 \\
\hline
\end{tabular}

No gráfico 2, observa-se que a primeira dosagem está com um bom padrão de atualização, já a segunda dosagem e os reforços de cada vacina não estão sendo seguidos adequadamente, havendo a necessidade de melhorar o acompanhamento e aconselhamento sobre a importância de vacinar. Em relação à idade das crianças que estavam em atraso vacinal, a faixa etária de maior prevalência ficaou entre 0 e 2 anos, onde $60 \%$ estavam desatualizadas, seguida por $40 \%$ das crianças entre 2 e 5 anos. Quando comparada a situação vacinal apenas de crianças menores de 2 anos, observa-se que $44 \%$ delas estão atualizadas, enquanto $25 \%$ das crianças acima de 2 anos tem 0 calendário adequado $(p=0,02)$ (Gráfico 3).

Levando em consideração auxílio governamental, observa-se que $55 \%$ dos beneficiários apresentam alguma vacina em atraso. $(p=0,0003)$ (Gráfico 4).

Outra questão relevante é o Estado Civil das mães. Observa-se que a maioria das casadas estavam com calendário em desatualização, 61 $(64 \%)$ casadas estavam atrasadas, enquanto $19(67 \%)$ solteiras estavam em desatualização. Do total geral de mulheres, 126 entrevistadas, 95 eram casadas e 28 eram solteiras. $(p=0,375)$ (Gráfico 5).

Considerando a escolaridade das mães das crianças em atraso, a maioria possui tempo de estudo de até no máximo o Ensino Médio Completo, o que corresponderia a cerca de $94 \%$. Enquanto as mães de crianças com calendários atualizados apresentam $74 \%$ escolaridade acima do Ensino Fundamental completo, contudo não observou-se significância nessa associação $(p=0,38)$ (Gráfico 6). 
Gráfico 2 - Análise de Pareto: dosagens mais atrasadas

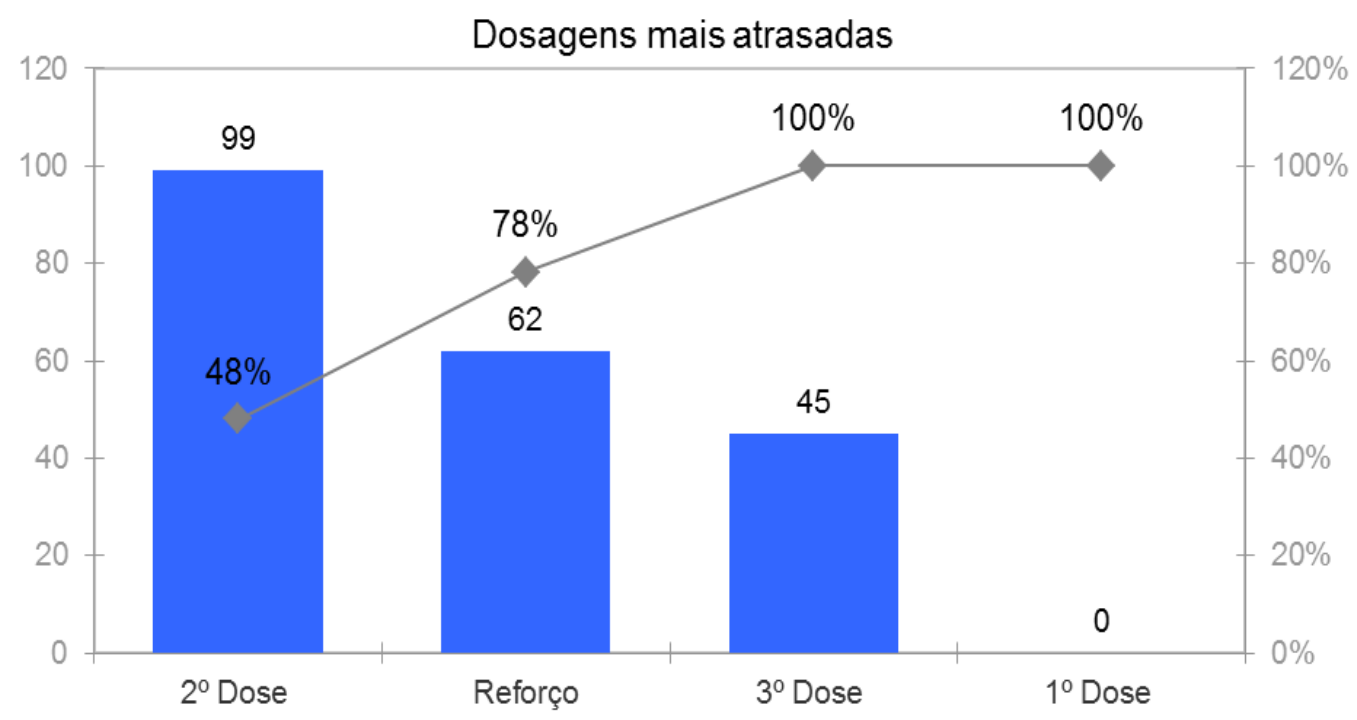

Gráfico 3 - Vacinação por idade

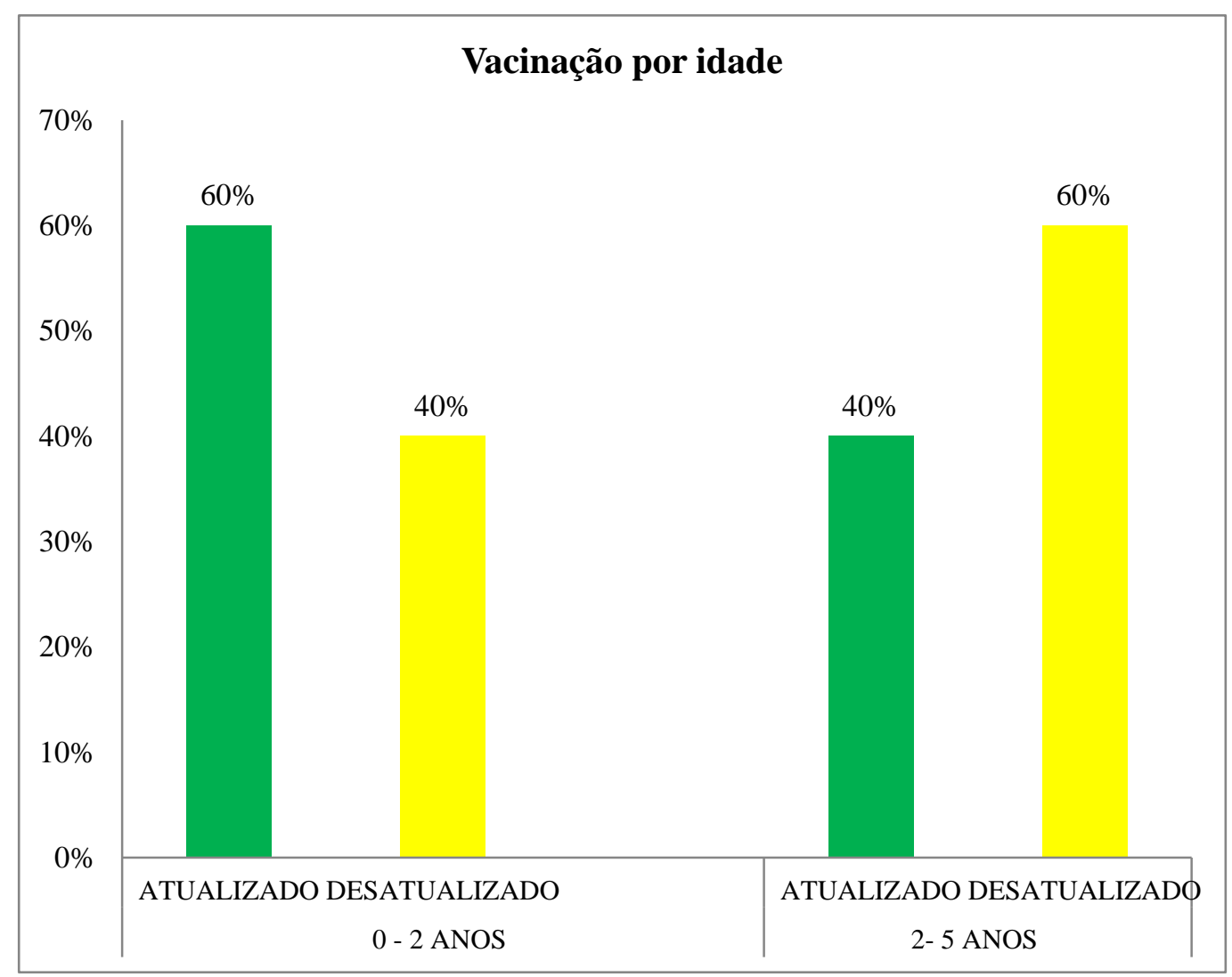


Gráfico 4 - Auxílio governamental

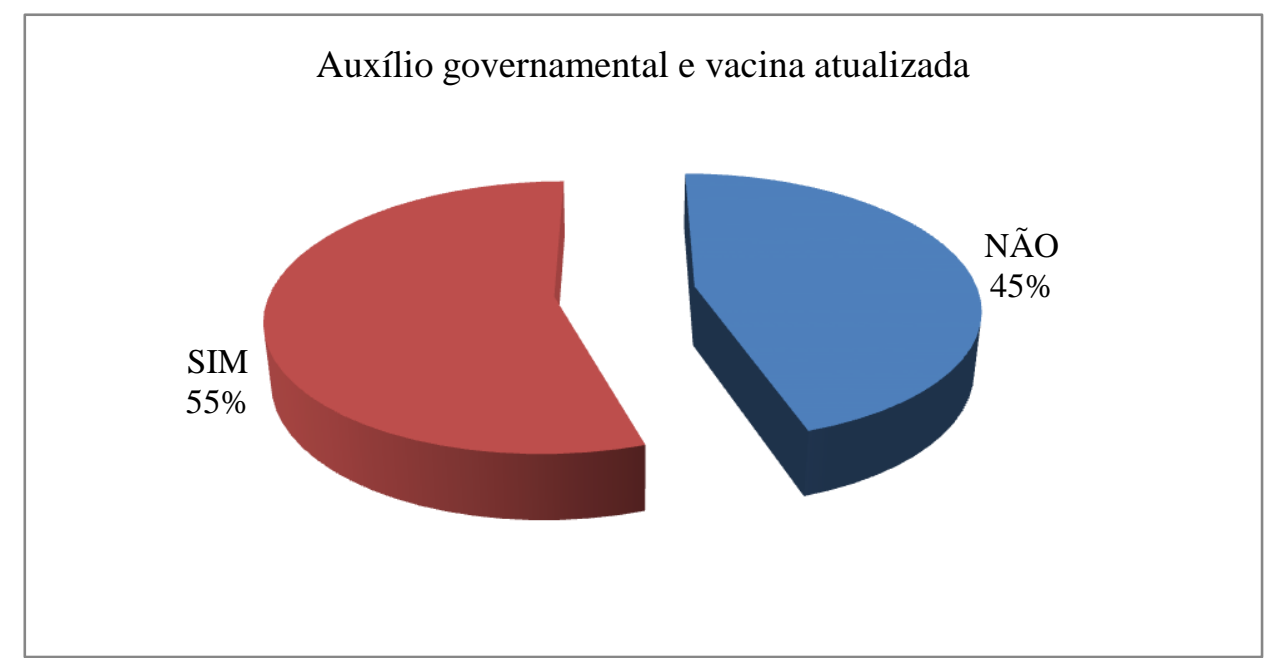

Gráfico 5 - Estado civil das mães

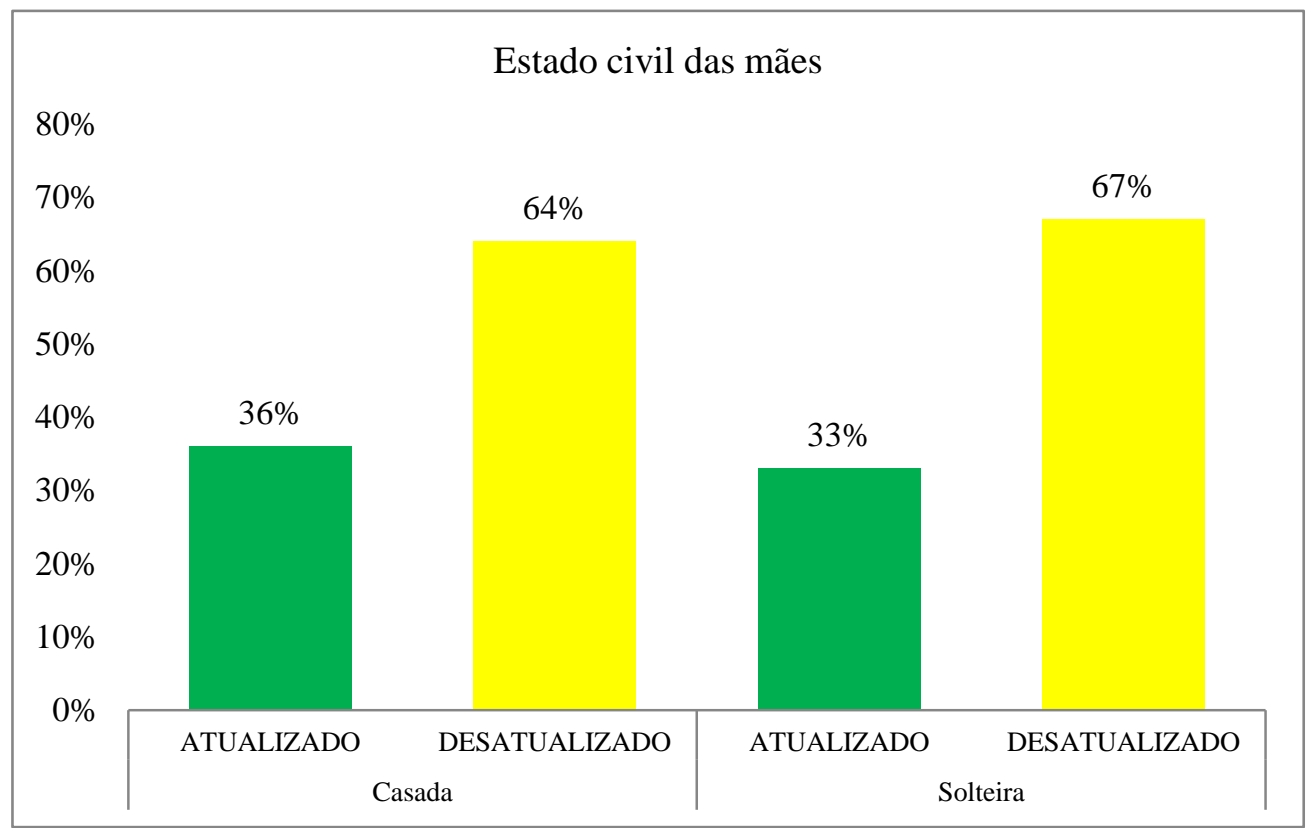


Gráfico 6 - Vacinação por escolaridade

Vacinação por escolariade

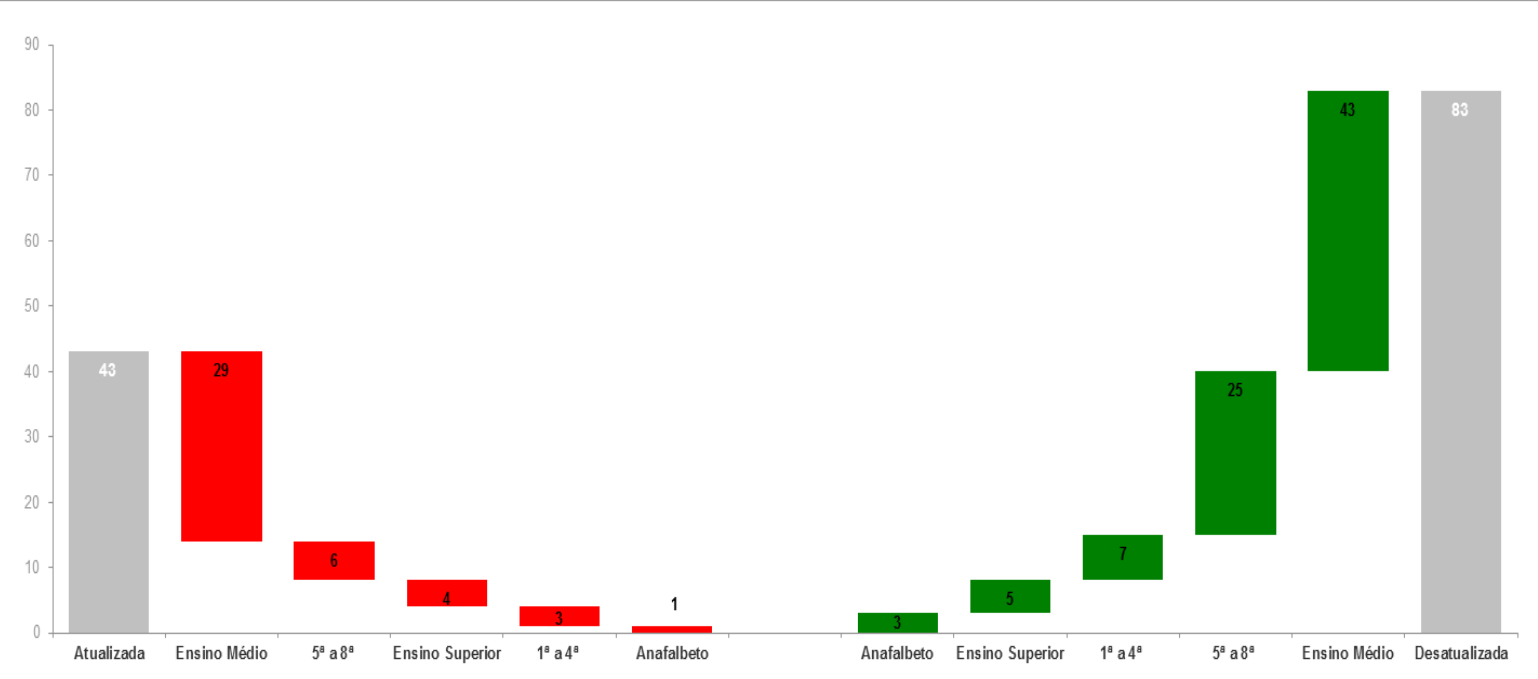

Em relação ao número de filhos das mães com vacina em atraso, constata-se que mais de $75 \%$ tem mais de 2 filhos, enquanto mães com filhos com situação vacinal atualizada apresentam 1 filho em $70 \%$ das situações $(p=0,25)$ (Gráfico 7 ).

Gráfico 7 - Número de filhos

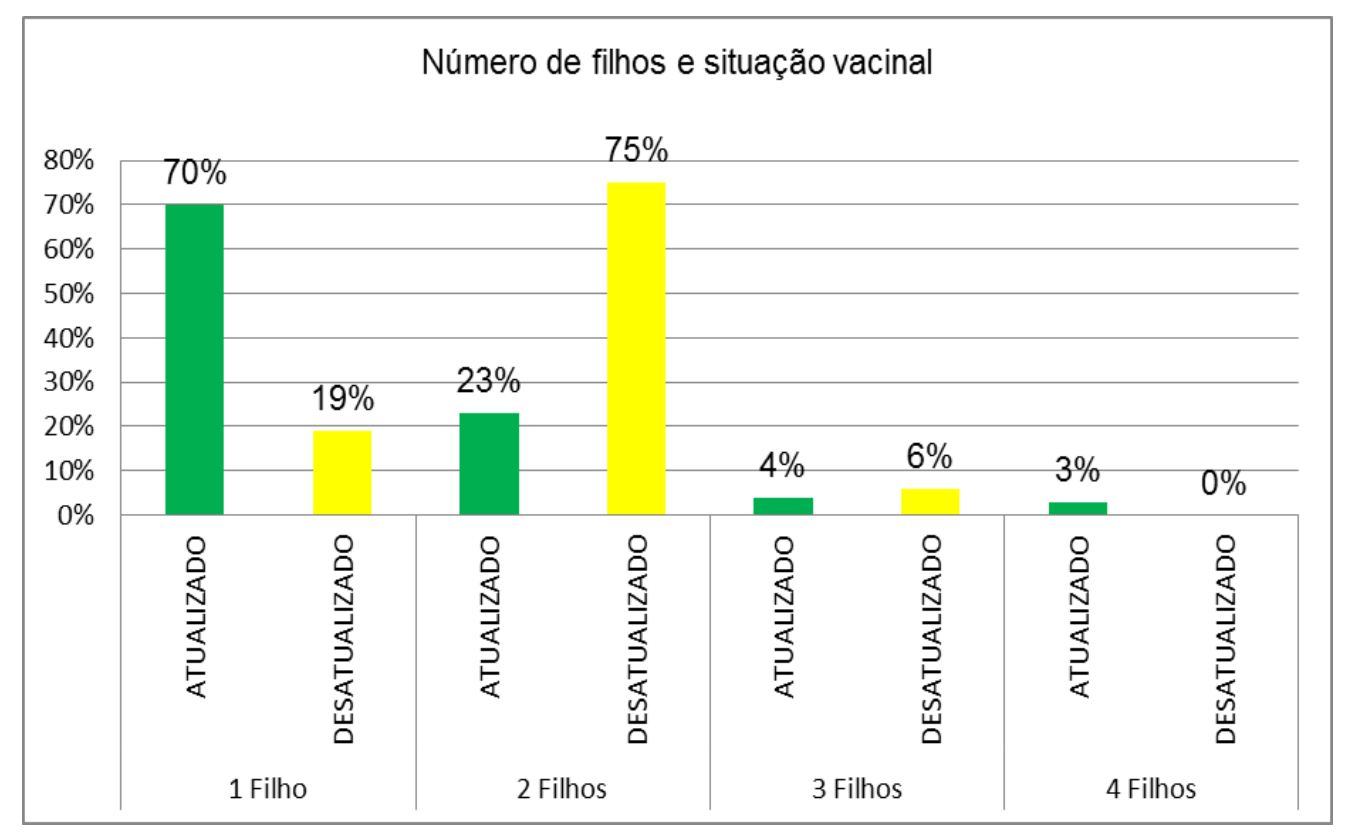




\section{Discussão}

Observou-se que cerca de $66 \%$ das crianças apresentaram situação vacinal de atraso. Um número relativamente elevado. Ao considerarse o motivo para que isso venha acontecendo, várias razões devem ser consideradas, como localização das Unidades Básicas de Saúde, esquecimento da data correta da vacinação, falta de acompanhamento adequado e de esclarecimento devido para a real necessidade de se ter um calendário vacinal em dia e, principalmente, a quantidade de doses necessárias para cada vacina. ${ }^{3}$

A tabela 2 demonstra as vacinas com maior desatualização, destacando-se a Pentavalente, a Pneumocócica e a VIP/VOP. De acordo com um estudo realizado por Tertuliano e Stein ${ }^{15}$, as vacinas que apresentavam três doses ou mais para a imunização das crianças apresentam um percentual de atraso mais elevado, que justifica 0 atraso da vacina pneumocócica. A observação de atraso na aplicação das vacinas, especialmente das segundas doses e reforço, aponta a necessidade de melhoria das estratégias de busca de faltosos. Pois do somatório geral, observou-se que todas aquelas com a necessidade de reforço foram descontinuadas pelas mães. Outra demonstração de que 0 grande número de dosagens dificulta a continuação da vacinação é o fato de que todas as crianças estavam com as primeiras doses efetuadas. Em especial destaque para a BCG e para a Febre Amarela, todas estavam atualizadas.

Esse atraso vacinal das dosagens subseqüentes mais uma vez remonta à necessidade de se ter uma atenção primária mais atuante com a população, pois a atualização vacinal é diretamente relacionada com a qualidade de vida de uma população, não sendo aceitável a perda da continuidade do seguimento adequado destas crianças. Alguns estudos já apresentaram solução para esse problema, de acordo com Luhm et al. ${ }^{16}$. relembrar os faltosos sobre o dia da vacinação seria uma boa estratégia, o que poderia ser feito com a instauração de prontuários informatizados, com agendamento eletrônico. Nesse estudo, a cobertura vacinal após a instauração de um sistema informatizado chegou a $95,3 \%$.

Observando-se os resultados, constata-se que $94 \%$ das mães possuem escolaridade de até no máximo o Ensino Médio Completo, evidenciando um nível de escolaridade de médio a baixo, quando comparadas a quem possui um tempo de estudo maior, observa-se uma diferença de $88 \%$, pois nesse último grupo apenas $6 \%$ estavam desatualizados. De acordo com Gonçalves e Machado ${ }^{17}$, quanto maior a escolaridade materna, maior a tendência de adaptarem-se à tecnologia médica e fazerem uso mais rotineiro dos serviços de saúde, buscando os serviços de maneira preventiva. Daí a necessidade de melhor esclarecimento sobre a importância da vacina às mamães, nas consultas de rotina da Pediatria.

Outro ponto que remonta ao desconhecimento da população sobre o momento ideal e a importância de se vacinar é a faixa etária que possui o maior atraso do calendário imune. Cerca de $60 \%$ das crianças com menos de 2 anos possuem calendário em atraso. A maioria das vacinas estão indicadas para serem feitas antes dos 2 anos de idade, no mínimo, até a $4^{\mathrm{a}}$ tomada. A exemplo disso, tem-se: Pentavalente, Pneumocócica e a VIP/VOP que somaram as vacinas mais desatualizadas. Segundo Gatti et al. ${ }^{18}$, uma vez com o calendário em 
atraso, as crianças tornam-se sujeitas a agravos de saúde, possivelmente preveníveis, incorrendo em sério risco de saúde.

Apesar de estudos mostrarem que a condição financeira pudesse ser uma justificativa para desatualização por vários fatores, como dificuldade de acesso e dificuldades cotidianas, ${ }^{14} 0$ auxílio governamental nesse contexto deveria servir de estímulo para melhorias na assistência vacinal. Contudo, acabou-se revelando pouco influente na decisão de se vacinar ou não. Apenas 45\% apresentavam-se dentro do adequado, mostrando-se, portanto, que ainda há um grande desafio na luta de se atualizar a situação imune das crianças, pois mesmo os que são instigados pelo sistema governamental a procurarem a assistência em saúde, continuam se mostrando pouco interessados em receber a atenção preventiva da imunização, permanecendo com 55\% das suas vacinas em atraso.

A cobertura vacinal mostrou-se prejudicada em famílias que possuem mais de um filho, cerca de $75 \%$ das famílias com mais de um filho apresentam déficit na atualização vacinal, demonstrando o que Molina et al. $^{19}$ já haviam constatado, evidenciando que uma família maior pode demandar mais tempo de trabalho para seu sustento, ou mais tempo para tarefas domésticas, podendo assim, prejudicar as visitas às unidades básicas de saúde para continuar o esquema de imunização. Em contrapartida, observou-se que há uma diferença pouco relevante no que se refere ao Estado Civil, tanto mulheres casadas quanto solteiras demonstram o mesmo compromisso com o filho na tentativa de atualizar a situação vacinal, desconsiderando 0 ambiente familiar mais hostil como uma causa provável de uma desatualização vacinal.

\section{Conclusão}

A cobertura vacinal ainda não é efetiva em São Luís - Maranhão. Percebeu-se um atraso vacinal de $66 \%$ com um erro padrão de 0,040 , os quais estão relacionados com fatores diversos. Seja por dificuldade do sequenciamento de vacinas com mais de uma dose, seja por uma situação familiar conturbada, ou pelo número de filhos. O certo é que há uma necessidade de se melhorar a cobertura vacinal dessas crianças.

Em contrapartida, observa-se que 0 Estado Civil pouco se diferenciou em carteiras atualizadas e desatualizadas, mostrando que existe pouca influência da situação conjugal, observando-se unicamente este parâmetro. Já os parâmetros menor escolaridade da mãe e maior número de filhos, mostram maior percentual de desatualização vacinal.

A atualização vacinal depende do cuidador da criança e da Unidade de Saúde pela qual ela é assistida, por isso, para obter um êxito vacinal maior, é necessário fomentar a conscientização materna, buscar ativamente as crianças na comunidade, e observar e revisar constantemente as carteiras de vacinação.

Somando-se a isso, é de total relevância capacitar a Rede de Atenção Básica, para que seja capaz de educar os pacientes sobre a importância da vacina, deixando de lado crenças populares e a sua falta de conhecimento, para assim obter uma saúde preventiva mais adequada. 


\section{Referências}

1. Amorim MNS. Importância da vacinação para prevenção de doenças: conscientização de pais

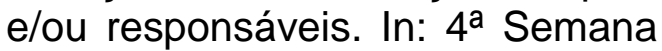
de Iniciação Científica Juazeiro do Norte; 2012; Juazeiro do Norte; 2012.

2. Farhat $\mathrm{CK}$, Carvalho LHFR, Succi RCM. Infectologia pediátrica. $3^{\text {a }}$ ed. São Paulo: Atheneu; 2007.

3. Gil C, Mendonça LH, Silva VRA. Vacinas: orientações sobre vacinas para o usuário de serviço de saúde: importância da vacinação completa. Bebedouro: Unifafibe; 2011.

4. Antunes LJ. Imunologia básica. São Paulo: Atheneu; 1999.

5. Feijó RB, Sáfadi MAP. Imunizações: três séculos de uma história de sucessos e constantes desafios. J Pediatr. 2006;82(3 supl):s1-s3.

6. Homma A, Martins RM, Leal MLF, Freire MS, Couto AR. Atualização em vacinas, imunizações e inovação tecnológica. Ciênc Saúde Coletiva. 2011;16(2):445-58.

7. Carneiro SG, Ribeiro TT, Cardoso MDT, Strapasson JF, Costa AFB, Guina FD. Avaliação da cobertura vacinal em crianças de 2 meses a 5 anos na Estratégia Saúde da Família [Monografia]. Volta Redonda: Centro Universitário de Volta Redonda; 2012.

8. Crepe CA. Introduzindo a imunologia: vacinas. Apucarana: Secretaria de Estado da Educação do Paraná; 2009.
9. Brasil. Ministério da Saúde. Programa Nacional de Imunização. Apresentação [Internet]. [acesso 2015 jan 15]. Disponível em: http://pni.datasus.gov.br/apresenta ção.asp.

10. Brasil. Ministério da Saúde. Secretaria de Vigilância em Saúde. Departamento de Vigilância das Doenças Transmissíveis. Nota no 143/CGPNI/DEVIT/SUS/MS

[Interent]. [acesso 2015 jan 20]. Disponível em: http://www.sgc.goias.gov.br/upload /arquivos/2015-02/notainformativa-143-2014-fa.pdf.

11. Silveira ASA, Silva BMF, Peres EC, Meneghin P. Controle de vacinação de crianças matriculadas em escolas municipais da cidade de São Paulo. Rev Esc Enferm. 2007;41(2):299-305.

12. Macinko J, Guanais FC, Souza MFM. Evaluation of the impact of the Family Health Program on infant mortality in Brazil 19902002. J Epidemiol Community Health. 2006;60(1):13-9.

13. Kreutz I, Gaiva MAM, Azevedo RCS. Determinantes socioculturais e históricos das práticas populares de prevenção e cura de doenças de um grupo cultural. Texto \& Contexto Enferm. 2006;15(1):8997.

14. Facchini L, Piccini R, Tomasi E, Silveira E, Siqueira $F$, Rodrigues M. Desempenho do PSF no Sul e no Nordeste do Brasil: avaliação institucional e epidemiológica da Atenção Básica à Saúde. Ciênc Saúde Coletiva. 2006;11:669-81. 
15. Tertuliano GC, Stein AT. Atraso vacinal e seus determinantes: um estudo em localidade atendida pela Estratégia Saúde da Família. Ciênc Saúde Coletiva. 2011;16(2):523-30.

16. Luhm KR, Cardoso MRA, Waldman EA. Cobertura vacinal em menores de dois anos a partir de registro informatizado de imunização em Curitiba - PR. Rev Saúde Pública. 2011;45(1):90-8.

17. Gonçalves SML, Machado MFAS. Opinião de um grupo de cuidadores sobre a imunização básica. Rev RENE. 2008;9(1):4551.

18. Gatti MAN, Oliveira LR. Crianças faltosas à vacinação, condições de vida da família e concepção sobre vacina: um inquérito domiciliar. Salusvita. 2005;24(3):427-36.

19. Molina AC, Godoy I, Carvalho LR, Caldas AL Jr. Situação vacinal infantil e características individuais e familiares do interior de São Paulo. Acta Sci. 2007;29(2):99106. 